attack the most healthy people. As I once heard Mr. Jalcolm Morris epigrammatically express it, "It is a disease of health." Most practitioners would admit the truth of this so far as the general health of the patient is concerned. Yet the lesions in psoriasis are well marked and their morbid snatomy accurately known. There is presumably a cause if we could only unravel the tangled web leading to it.

South-street, Park-lane.

\section{CASE OF PUERPERAL PERITONITIS.}

By Frank Sturges, L.R.C.P. Lond., \&e.

THe following case seems to present points of sufficient interest to warrant $\mathrm{my}$ wish to obtrude it upon the notice of the readers of THE LANCET. I will first give very briefly my daily notes.

Mrs, G-, aged thirty, multipara, a pale and delicatelooking woman, was delivered of a living child on Aug, 22nd at 7 P.M., after a labour that would have been quite normal but for a somewhat prolonged first stage (about ten hours). The placenta was expressed without any difficulty a little later-Aug. 24th: Slept little, and complains of great abdominal pain. Light tapping with fingers reveals extreme tenderness over hypogastric and both iliac regions. Temperacure $99^{\circ} 4^{\circ}$; pulse 80 . Has vomited, and feels sick. Ordered milk and lime-water diet, half a grain of opium every four hours, and mustard and linseed poultices continually.25th: Vomited and retched a good deal since last note. Jochia small in quantity, but very offensive. Peritonitis most acute over the whole abdomen. Temperature $1006^{\circ}$ pulse 100, feeble. The uterine cavity was washed out with water coloured by iodine tincture. Ordered half a grain of opium overy three hours; poultices to be continued; a diet of milk and lime-water, and a little strong beef-tea; and a dessertspoonful of brandy every four hours.-26th: Passed a better night. Has not vomited, and says she is much better. Light palpation still causes pain, but not so severe. Lochia more in quantity and less offensive. Temperature $99 \cdot 2^{\circ}$; pulse 80 , of better volume. Uterus again washed out, and treatment continued.-27th : Had a good night, and is much better. Lochia quite sweet. Light palpation causes little or no pain. Temperature $98.4^{\circ}$; pulse 64 , and of fair volume. Diet to be milk and beef-tea; brandy omitted, and half a grain of opium given every six hours. Uterus again washed out. From this period nothing of note occurred, the convalescence being rapid and complete.

Now, this case is most interesting to me, probably largely on account of its gratifying termination. I have always regarded acute peritonitis coming on so soon (about thirty hours) after the commencement of the puerperal period as almost necessarily fatal, and on Aug. 25th the patient was so very ill that I hardly thought she could recover. With regard to the causation, there is much of interest. The moman was living as caretaker in an empty house, a house that had not been properly inhabited for some considerable time. In this house were three waterclosets-one, scarcely ever used, on the same floor as the room in which the patient was contined. And I believe that, although I was informed there was plenty of water and I never detected any drainage smell, the flushing of this closet had been much neglected. This, then, would be a sufficient cause, only there is something else to be told. The nurse who was present at the birth was suffering from an attack of acute tonsillitis, which rendered her barely able to discharge her duties; and when she showed me her throat I was greatly exercised in my mind as to whether I ought not to send her home, and whether, if the stayed, she could convey by any possibility septic poison to my patient. However, she stayed till Aug. $24 \mathrm{th}$, when I 7as informed, on paying my morning visit, she had gone home, feeling too ill to attend to her work. Thus, for two dights the nurse had slept with the lying-in woman, and some time during the second night the peritonitis came on, And, I might add, the nurse went away, and the patient got better: was it because the cause was removed? And then, lastly, concerning the treatment. I have already told how I treated the case; but the nurse treated it also, and in this way. On the morning of Aug. 24th, before going bome she gave the patient, without any authority, six much advertised patent pills. I did not hear of this till the following day, when I was told that Mrs. G- had had 5 tro actions of the bowels causing such intense pain that she twice fainted. Mr. Lawson Tait has, I believe, advocated the treatment of these cases by Epsom salts; and although it would seem to me to require all Mr. Tait's great reputation to put that treatment into practice, I would not take upon myself to say that these pills administered by the nurse had not something to do with the recovery. For they were given early on the 24 th ; they acted twice in the night on the morning of the 25 th the patient was much worse, but during the day she changed for the better. We must also bear in mind, however, that on the morning of the 25 th I injested the uterus with a solution of iodine, and by that time, too, notwithstanding aperient pills, the opium and counter-irritation were beginning to have effect. Should it be my misfortune to have anotber case of the kind, I shall certainly treat it with iodine irrigation, opium, and counterirritation, and not with the aforesaid pills or Epsom salts. Still, I have considered it right to record this case in its entirety because of its peculiar and speculative interest, and because of the terribly fatal nature of the disease; and I ask members of the profession to take all the facts into their careful consideration and draw their own conclusions. Beckenham.

\section{VERY RARE PRESENTATION IN MIDWIFERY}

\section{BY W. H. BorhaM, L.R.C.P.E., M.R.C.S., L.M.}

ON Sept. 20ıh, 1887, Mrs. C-, aged thirty-two years, was being attended in her confinement with her sixth child by a midwife. She had been in labour for two days, and the midwife left her for about an hour. On her return she found a loop of the funis, three inches in length, protruding from the vagina, and "something wrong above" in connexion with the head of the child.

The midwife sought for my attendance. Upon examination I found the cord hanging external to the vulva in a loop about the length stated; there was a slight pulsation in it, and it was getting cold. Upon introducing my fingers, I found the palm of the child's left hand was flat and pronated on the side of the child's occiput between it and the mother's sacrum. In the interim of the pains, which were flagging, I at once introduced $\mathrm{my}$ hand into the vagina, pushed up the child's hand and head, then gradually insinuated my right hand into the uterus and grasped the left foot, turned the child, and in a few minutes delivered the mother of a female child. It had suspended respiration, but the heart was still pulsating. With the usual treatment of warm bath, \&c., the child was restored, and both are now quite well.

During a forty years' experience, and after attending some thousands of cases, I have never met with a similar presentation, nor do I remember reading of such a one by any authority. The fact of the hand resting on the head and the cord lying along the side of the wrist and thumb prevented that pressure upon the cord which would otherwise certainly have cut off the circulation of the blood and killed the child. Speedy version and delivery were necessary to save the child. All the parts of the female pelvis were capacious, and the soft structures amply relaxed. Some authorities state that both feet should be grasped and drawn down together in this operation, but most experienced accoucheurs in this operation, 1 think, will agree with me when 1 say that this is more easily said than done. To grasp both feet, which may be widely apart, with a cramped hand in the uterus, where the liquor amnii has escaped, is no easy task to accomplish, especially when one has so little time to secure a living child. It is better to be sure and bring the first grasped foot down, especially in such a case as the above, and $I$ have never had any difficulty in easily delivering in this way. The joints and tissues in the newborn infant are so supple and flexible that no danger need be apprehended if carefully manipulated.

The mother of this child, when she was five months pregnant, fell downstairs, which may have altered the position of the fotus in utero, and caused this unusual presentation. Fulham.

West Kent Medico-Chirurgical Soctety. - The following office-bearers have been elected for the present session:-President : Mr. J. Brindley James. Vice-presidents: Dr. Peter Horrocks, Mr. Thomas Moore. Council : Mr. G. H. Cable, Dr. Ernest Clarke, Mr. Peter Cooper, Dr. W. Collingridge, Dr. Alexander Forsyth, Mr. Frederick Moon, Mr. J. Poland. Treasurer : Dr. Prior Purvis. Secretary: Mr. H.W. Roberts. Librarian : Dr. Ernest Clarke. 